\title{
RUMAH KOPI
}

\author{
Henny Angkasa ${ }^{1)}$, Maria Veronica Gandha ${ }^{2)}$ \\ 1) Program Studi S1 Arsitektur, Fakultas Teknik, Universitas Tarumanagara, hennyangkasa@gmail.com \\ ${ }^{2)}$ Program Studi S1 Arsitektur, Fakultas Teknik, Universitas Tarumanagara, mariag@ft.untar.ac.id
}

\begin{abstract}
Abstrak
Kopi sebagai salah satu komoditas utama Indonesia berada di urutan ke sepuluh statistik komoditas ekspor utama Indonesia edisi tanggal 15 Januari 2019, dikutip dari Kementrian Perdagangan Republik Indonesia. Namun, kopi selain sebagai komoditas ekspor, masih memiliki banyak potensi. Salah satunya adalah pada sektor pariwisata dimana negara seperti Kolombia telah berhasil menarik lima juta pengunjung pada tahun 2009 dengan Taman Nasional Kopi miliknya. Indonesia sebagai negara keempat produksi kopi terbesar di dunia dengan 18 karakter biji yang tersebar dari sabang sampai merauke dapat mengadopsi kekayaan kopi tersebut sebagai identitas negara dan sebagai destinasi wisata. Berdasarkan ini, Rumah Kopi pun dirancang dengan tujuan untuk membangun ikon kopi di Indonesia. Dengan sentuhan fantasi, Rumah Kopi akan membawa pengunjung menjelajahi sejarah kopi dari pertama kali ia ditemukan sampai dengan sekarang. Perjalanan ini kemudian diklasifikasikan berdasarkan empat era yang dimulai secara berurutan dari zaman klasik, abad pertengahan, zaman renaissance, dan yang terakhir adalah zaman kontemporer.
\end{abstract}

Kata kunci: Fantasi, Indonesia, Kopi, Zaman, Wisata.

\begin{abstract}
Coffee is a highly traded commodity and was placed tenth on the 15th January 2019 top exported commodities chart by the Ministry of Trade in Indonesia. However, coffee has so much more potential to tap into aside from trading, one of which is the tourism sector where country such as Colombia has managed to receive five million visitors in 2009 with its National Coffee Park. Indonesia as the fourth highest coffee producer in the world, with its 18 characters of coffee beans spread across the archipelago, has every chance to apply its coffee's identity as a travel destination. Based on these facts, House of Coffee is then designed in the purpose to build an icon of coffee in Indonesia, with a Coffee Fantasy twist that takes visitors by their hands to travel in the history of Coffee since its first discovery. The journey is then based on the four major classifications of age, which in order starts from the classical age, the medieval age, the renaissance, and last but not least the contemporary age.
\end{abstract}

Keywords: Fantasy, Indonesia, Coffee, Age, Tourism

\section{PENDAHULUAN}

Minat masyarakat terhadap kopi dari zaman ke zaman kian meningkat. Peningkatan dalam konsumsi kopi di dunia bahkan mampu membantu beberapa daerah penghasil kopi seperti di Bondowoso, Indonesia dalam menurunkan angka kemiskinan dari 24 persen menjadi 14 persen, dikutip dari Menteri Desa, Pembangunan Daerah Tertinggal dan Transmigrasi Indonesia, Eko Putro Sandjojo. ${ }^{1}$ Cina yang sejak dahulu dikenal sebagai negeri teh saat ini pun telah mengadopsi kopi sebagai minuman kesehariannya sehingga retail kopi seperti Starbucks membuka satu cabang setiap 15 jam di Cina. Total gerai kopi di Shanghai sendiri telah mencapai 6500 toko.

Budaya 'Ngopi' merupakan manifestasi dari budaya millennial terutama di kota metropolitan di mana kopi diyakini dapat meningkatkan produktivitas. Namun, selain kaum millennial, masyarakat dari berbagai kalangan usia juga menggemari kopi dengan berbagai 
alasan, antara lain sebagai social lubricant dalam membahas bisnis, sebagai tempat nongkrong, sebagai tempat nugas, dan sebagai seni untuk dibagikan di sosial media. Minuman ini meskipun besifat sederhana memiliki potensi wisata yang sangat besar.

Indonesia merupakan negara pengekspor dan produksi kopi keempat di dunia. Perkebunan kopi di Indonesia tersebar dari Sabang sampai Merauke dan merupakan rumah dari 18 karakter bji kopi dari tumbuhan Arabica, Robusta, dan Liberica. Setiap daerah memiliki karakter biji kopi yang berbeda, dengan pulau Sumatra, Jawa dan Sulawesi menjadi sorotan dunia. Presiden RI, Joko Widodo dalam vlog miliknya juga mendukung pernyataan tersebut. la juga mengupload beberapa kunjungannya ke kedai kopi lokal, salah satunya yang terbaru di Sejiwa Café, Bandung dimana ia mencoba salah satu kopi termahal di dunia yang berasal dari Gunung Puntang, Jawa Barat dan menggalakkan apresiasi masyarakat terhadap brand kopi lokal.

Bank BRI telah menyalurkan kredit sebesar Rp 1,4 triliun kepada 48.000 pengusaha kopi, dari penanam, produsen, hingga distributor. "Bank BRI juga berkomitmen untuk membantu petani dan pelaku kopi memajukan Kopi Nusatara," ucap Direktur Keuangan BRI Haru Koesmahargyo. Harian Kompas bekerja sama dengan PT Bank Rakyat Indonesia Tbk juga telah menggelar Festival Kopi Nusantara yang berlangsung Kamis (19/7/2018) hingga Minggu (22/7/2018) mendatang di Bentara Budaya Jakarta.

Festival Kopi Nusantara merupakan rangkaian ekspedisi jurnalistik harian Kompas bertema Jelajah Kopi Nusantara yang digelar sejak April 2018. Festival Kopi Nusantara menjadi cara Kompas "mengenalkan" kopi di tanah air Indonesia khalayak ramai. Festival menghadirkan stan petani kopi dari beberapa wilayah di Indonesia yang disertai dengan sejumlah stan kedai kopi dan kedai alat-alat kopi, pameran foto tentang kopi selama pelaksanaan Jelajah Kopi Nusantara, serta diskusi, kompetisi roasting dan brewing. Selain pameran kopi, kegiatan dan hiburan lain juga akan digelar, seperti diskusi, pameran foto hasil liputan "Jelajah Kopi Nusantara", kelas roasting, kompetisi manual browing, cup tasting, peramal, dan live music.

Ikon kopi memang belum terbangun dalam pariwisata Indonesia. Seandainya pariwisata dan kopi ditekuni, maka tidak mustahil branding kopi Indonesia akan menjadi lebih kuat dan pariwisata akan lebih bergeliat.

\section{KAJIAN LITERATUR}

Tumbuhan kopi dikenali oleh masyarakat melalui jenis pohon, jenis buah, dan turunan jenis buahnya yang disebut juga dengan varietas. Berdasarkan jenis pohonnya, tumbuhan ini terdiri dari Arabica, Robusta, dan Liberica. Proses Pengolahan (Bean to Cup) Kopi terdiri atas beberapa tahap. (lihat Diagram 1) .

Selain dari kualitas rasa kopi itu sendiri, suasana ruang berperan penting dalam menciptakan perasaan nikmatnya secangkir kopi. Juhani Pallasmaa dalam bukunya The Eyes of The Skin, menceritakan tentang kekuatan olfactory imagery / gambaran dari sensasi lidah yang mampu membangkitkan memori suatu tempat dan sensasi dari sentuhan yang terintegrasi dalam menciptakan suatu pengalaman yang mengesankan. Penglihatan akan warna tertentu dan detil bentuk dan tekstur akan diartikan ke tactile and oral sensations yang dimulai dari lidah hingga diterjemahkan oleh saraf otak. Hal ini kemudian membentuk sebuah sensory experience. Gelombang kebudayaan manusia terdiri dari 4 zaman, yaitu Zaman Klasik, $<5^{\text {th }}$ century, Abad Pertengahan, $5^{\text {th }}-15^{\text {th }}$ century, Renaisans dan Modern, $16^{\text {th }}-18^{\text {th }}$ century dan Zaman Kontemporer, $19^{\text {th }}$ century - present. 


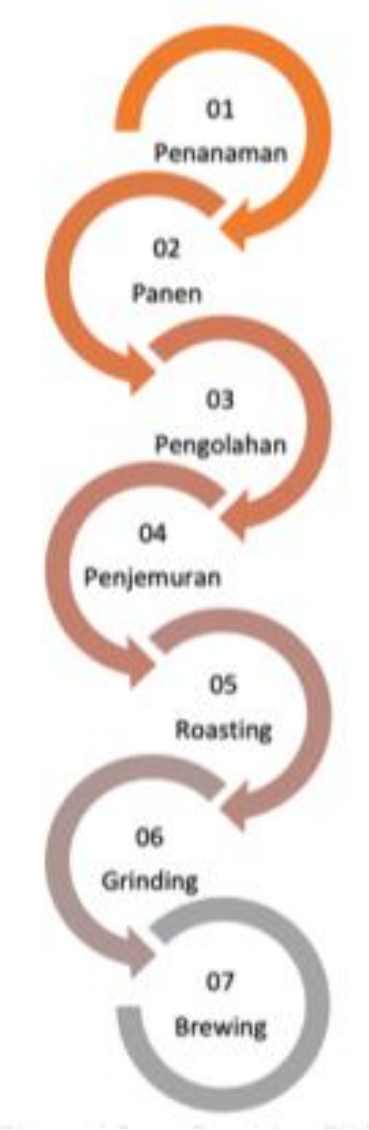

Gambar 1. Diagram Proses Pengolahan Biji Kopi Sumber: analisis penulis

\section{DISKUSI DAN HASIL}

\section{Program}

Program utama wisata rumah kopi ini akan dinikmati oleh pengunjung secara bertahap dimulai dari Mocha Potting Shed, Qahwah Cave, Kahvehanne, dan diakhiri di The Third Wave. Pengunjung akan dipandu dalam perjalanan untuk mengenal makna kopi setiap zaman ini. Setiap zaman akan memiliki sebuah age extension / ekstensi zaman yang memberikan opsi kepada pengunjung yang ingin menghabiskan waktu lebih di zaman tertentu.

Apabila tidak ingin menikmati / telah selesai menikmati age extension tersebut, pengunjung dapat melanjutkan perjalanannya ke zaman berikutnya. Setiap age extension merupakan program solitaire yang memiliki pintu masuk dan keluar tersendiri sehingga tidak terikat oleh rute perjalanan program utama.

\section{Mocha Potting Shed}

Area ini merupakan sebuah taman yang dirancang seperti hutan tropis dan di dalamnya terdapat pohon-pohon seperti angsana, bintangor, dan ketapang, yang memiliki ketinggian 4 5 meter dan diameter crown $2-4$ meter, beserta tumbuhan kopi yang berjenis Arabica, Robusta, dan Liberica. Di tengah hutan tersebut akan ada sebuah amphitheatre kecil yang menampilkan live music akustik atau disebut juga Kopikustik.

Rancangan pada area ini diharapkan dapat memberikan pengunjung suasana kosmosentris yang menembalikan mereka ke zaman klasik, dimana tumbuhan kopi dan manusia adalah 
bagian dari alam. Age extension pada zaman ini adalah area bercocok tanam yang mengajarkan pengunjung cara menanam tumbuhan kopi sebagai house plant.

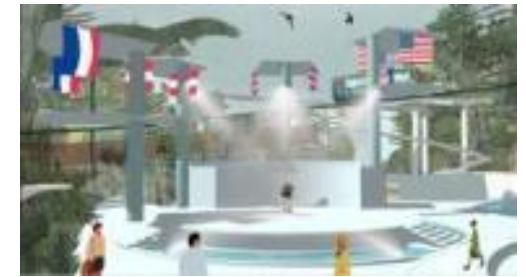

Gambar 1 Amphitheatre

Sumber: Dokumentasi Pribadi

\section{Qahwah Cave}

Area ini diawali dengan pengunjung menelusuri labirin gelap yang menjelaskan proses kopi dari saat pemanenan sampai menghasilkan green bean. Labirin gelap ini juga merepresentasikan abad pertengahan yang dikenal juga sebagai abad gelap. Masyarakat pada abad ini banyak melakukan perjalanan spiritual mencari makna hidup. Labirin ini kemudian pun akan menuntun pengunjung menuju sumber cahaya / pintu keluar dan melewati ramp melingkar yang dikelilingi oleh pohon-pohon tinggi dan bersifat outdoor. Pengunjung akan tiba di dataran dan disambut dengan papan cerita asal usul kopi dan bau kopi yang disajikan secara tradisional. Teknik roasting hanya menggunakan fireplace dan wajan.

Age extension pada zaman ini adalah area hygge yang dibentuk seperti kepompong dengan tujuan untuk memberikan pengunjung rasa terlindungi. Hygge merupakan salah satu filosofi hidup masyarakat Denmark yang mencari kesenangan dalam hal-hal kecil, seperti hal kecil, seperti membaca buku, menikmati secangkir teh / kopi, mengamati dedaunan pohon yang bergoyang, dll.

\section{Kahvehanne}

Area ini akan dinikmati oleh pengunjung dengan menggunakan kereta api yang akan membawa mereka menelusuri pulau-pulau bendera sesuai urutan alur distribusi kopi di dunia yang dimulai dari Amerika, Inggris, Austria, Perancis, dan berakhir di Indonesia. Zaman ini menceritakan perkembangan dunia manusia dilihat sebagai pencipta dunianya / faber mundi dengan bermunculannya berbagai jenis inovasi, salah satunya adalah kereta api. Pengunjung akan tiba di sebuah terminal kopi Indonesia dengan pulau Jawa, Sumatra, dan Sulawesi sebagai highlights pameran. Terminal ini didesain dengan bukaan berbentuk arch untuk mencirikan arsitektur klasik renaissance. Age extension pada zaman ini adalah area minum kopi ala Indonesia dengan cara ndeprok dan pengunjung dapat memilih cara penyajian kopi Indonesia yang cukup beragam.

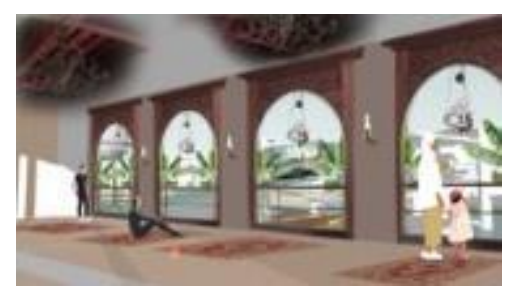

Gambar 2 Area Ndeprok

Sumber: Dokumentasi Pribadi

\section{The Third Wave}

Perjalanan pun berakhir di zaman kontemporer ini yang ditempuh oleh pengunjung dengan kereta api, kelanjutan dari terminal kopi Indonesia sebelumnya. Area ini akan menampilkan proses roasting coffee sampai dengan proses brewing coffee yang bersifat kekinian. Highlight 
rancangan pada zaman ini terletak pada plafon yang dilalui oleh pipa-pipa transparan yang mentransportasikan green bean dari silo outdoor menuju silo indoor untuk proses roasting dan menuju tabung coffee bar. Pengunjung di era ini akan mendalami rasa kopi yang sangat beragam secara detail dan mencoba inovasi-inovasi minuman kopi seperti cold brew.

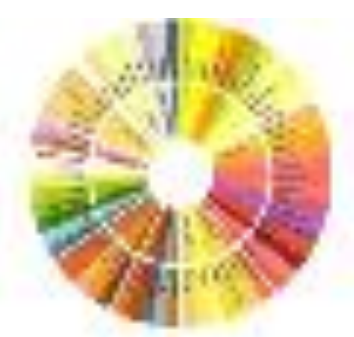

Gambar 3 Tasting Pallette Sumber: Google Image

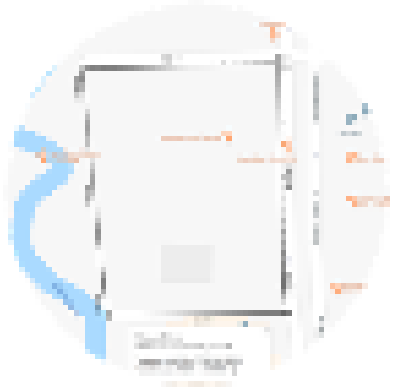

Gambar 4 Dimensi Tapak Sumber: Google Image

\section{Data Tapak}

$\begin{array}{ll}\text { Luas Lahan } & : 8782 \mathrm{~m}^{2} \\ \text { KDB } & : 4,391 \mathrm{~m}^{2} \\ \text { KLB } & : 17,564 \mathrm{~m}^{2} \\ \text { KTB } & : 4,931 \mathrm{~m}^{2} \\ \text { KB } & : 4 \\ \text { KDH } & : 30174\end{array}$
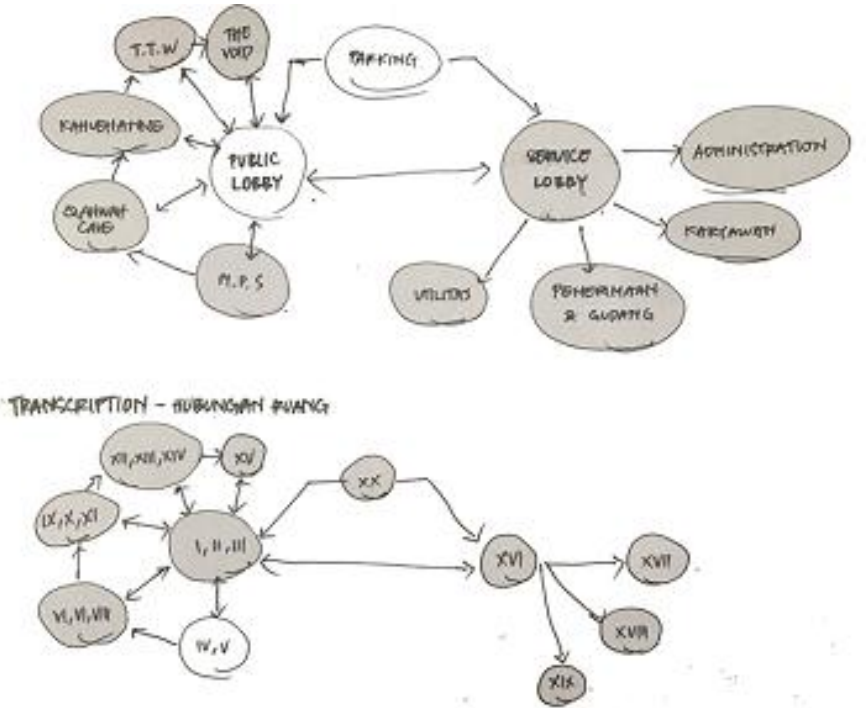

Gambar 5. Skema hubungan antar ruang 


\section{Metode Perancangan}

Menggunakan metode perancangan diagram, proses gubahan massa Rumah Kopi dimulai dari hasil transkripsi biji kopi lintong yang kemudian diberi volume sesuai dengan luas program ruang. Massa representatif ini kemudian pun dieksperimen kemungkinannya dengan panduan skema hubungan antar ruang (lihat Gambar 5).

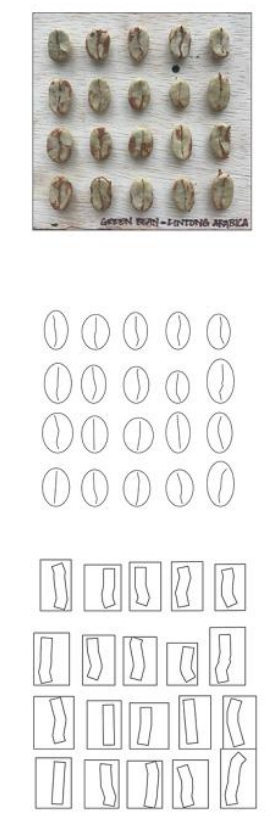

\section{Gambar 5. Proses Gubahan Massa}

Sumber: Google Image

\section{KESIMPULAN DAN SARAN}

Rumah Kopi merupakan salah satu ikon destinasi wisata di kota Jakarta yang didasari oleh latar belakang untuk menjadikan kopi sebagai salah identitas bangsa Indonesia. Pengunjung akan diajak untuk melakukan perjalanan untuk mengenal makna kopi di empat gelombang budaya yang berbeda yang dirancang dengan sentuhan fantasi. Empat gelombang tersebut antara lain adalah zaman klasik, abad pertengahan, zaman renaissance, dan zaman kontemporer.

Proyek ini bersituasi di Jalan Kemang Raya, Jakarta Selatan. Pemilihan daerah ini didasari atas pertimbangan telah terbentuknya infrastruktur pariwisata dan coffee drinking scene area tersebut. Tapak proyek dikelilingi oleh banyak hotel, café, bar, dan pusat perbelanjaan yang menunjang walkability. Dengan minimnya area hangout terbuka di Jakarta, area ini juga dapat menarik pengunjung lokal.

Proses desain rumah kopi ini menggunakan metode diagram Ben Van Berkel dan Caroline Bos dengan transkripsi biji kopi lintong yang kemudian diberi volume massa dan dieksperimentasi kombinasinya dengan diagram hubungan ruaang yang menjadi panduan untuk membentuk gubahan massa proyek ini. Perancangan setiap zaman juga disesuaikan dengan karakter masing-masing zaman tersebut.

Rumah Kopi ini diharapkan dapat menjadi sebuah sarana yang memfasilitasi kegiatankegiatan yang terkait dengan kopi dan menjadi sebuah ikon destinasi wisata yang memperkenalkan kopi sebagai salah satu kekayaan alam Indonesia. 


\section{UCAPAN TERIMA KASIH}

Puji dan syukur kepada Tuhan Yang Maha Esa atas segala rahmat dan berkat yang telah diberikan-Nya sehingga penulis dapat menyelesaikan tulisan yang berjudul HOUSE OF COFFEE/ RUMAH KOPI.

\section{REFERENSI}

Specht, Jan. (2014). Architectural Tourism : Building for Urban Travel Destinations. Hoffmann, James (2014). The World Atlas of Coffee : From Beans to Brewing - Coffees

Explored, Explained, and Enjoyed.

Pallasmaa, Juhani (2012). The Eyes of the Skin : Architecture and the Senses.

Jormakka, Kari (2008).

Basics Design Methods. Moldaver, Anette (2014). Coffee Obsession : Flavorful Beans, Barista Techniques, More than 100 Global Recipes.

Dashwood, Maxwell Colonna (2017). The Coffee Dictionary : An A-Z of Coffee, from Growing \& Roasting, to Brewing \& Tasting.

Moore, Rowan. (2017). The Bilbao Effect : How Frank Gehry's Guggenheim Started a Global Craze. www.theguardian.com.

Totok, Wijayanto. (2018). Jelajah Kopi Nusantara : Menyematkan Kopi dalam Geliat Wisata. jelajah.kompas.id.

Goodwin, Lindsey. (2018). The Origin of Coffee : Ethiopia and Yemen. www.thespruceeats.com Bakersville. Peter. (2013).The World's Most Historic Coffee Houses.

www.espressocoffee.quora.com. 